Check for updates

Cite this: Chem. Sci., 2019, 10, 9051

๑ All publication charges for this article have been paid for by the Royal Society of Chemistry

Received 1st July 2019

Accepted 3rd August 2019

DOI: $10.1039 / \mathrm{c} 9 \mathrm{sc} 03215 \mathrm{k}$

rsc.li/chemical-science

\section{Divergent Pd-catalyzed cross-coupling of allenyloxazolidinones to give chiral 1,3-dienes and vinyloxazolidinones $\dagger$}

\author{
Ronald W. Brown, (D) ${ }^{a}$ Farzad Zamani, ${ }^{a}$ Michael G. Gardiner, (D) ${ }^{b}$ Haibo Yu, (D) ${ }^{a}$ \\ Stephen G. Pyne (D) and Christopher J. T. Hyland (D) *a
}

The divergent reactivity of 5-allenyloxazolidinones has been explored. This novel building block undergoes $\mathrm{Pd}(0)$-catalyzed cross-coupling with boronic acids to form a wide range of chiral 1,3-dienes and pharmaceutically useful vinyloxazolidinones, the chemoselectivity being tightly controlled by a simple switch in additive.
The synthetic utility of strained vinylic building blocks such as vinylaziridines and vinyloxazolidinones (Scheme 1A) in constructing high-value N-containing scaffolds is well-established. Upon activation by low-valent transition metals such as palladium(0), 2-vinylaziridines and 5-vinyloxazolidinones are known to undergo direct cross-coupling and cycloaddition reactions, ${ }^{\mathbf{1 - 5}}$ which often proceed via a $\mathrm{Pd}-\pi$-allyl intermediate. Systems with cumulated double bonds, most notably the allene unit, are valuable synthetic tools as the reactive 1,2-diene structure opens up reaction pathways otherwise inaccessible to simple vinyl systems. The high degree of unsaturation facilitates tandem, multistep reactivity, and can be retained in the products of cycloaddition and carbometalation processes. ${ }^{6}$ It is therefore surprising that the allenyl analogues of vinylaziridines and vinyloxazolidinones have not been investigated to date.

We have recently developed a novel class of enantioenriched 5 -allenyloxazolidinones (Scheme 1B) derived from $\mathrm{L}$ - $\alpha$-amino aldehydes, ${ }^{7}$ serving as an entirely new building block with complementary reactivity to the aforementioned vinylic systems. We have recently reported that these systems can be converted in situ to 1,3-(E)-enynes and precede the dual goldcatalyzed cycloaromatization of unconjugated- $(E)$-enediynes to enantioenriched isoindolines. ${ }^{8}$ However, direct utilization of the allene unit of this building block in transition metalcatalyzed reactions has the potential to unlock new reactivity. Like its vinyl counterpart, the reactivity of the allene moiety can be harnessed through palladium catalysis, ${ }^{9}$ notably $\operatorname{Pd}(0)$ -

${ }^{a}$ School of Chemistry and Molecular Bioscience, and Molecular Horizons Research Institute, University of Wollongong, Wollongong 2522, NSW, Australia. E-mail: chrhyl@uow.edu.au

${ }^{b}$ Research School of Chemistry, Australian National University, Canberra 2601, Australia.E-mail: michael.gardiner@anu.edu.au

$\dagger$ Electronic supplementary information (ESI) available. CCDC 1919153 and 1919154. For ESI and crystallographic data in CIF or other electronic format see DOI: $10.1039 / \mathrm{c} 9 \mathrm{sc} 03215 \mathrm{k}$ catalyzed cross-coupling reactions with boronic acids and allenylcarbinol derivatives to give substituted 1,3 -dienes, ${ }^{\mathbf{1 0}}$ a process first reported by Miyaura in $1994 .{ }^{10 a}$ The mild conditions associated with such routes to these invaluable precursors to complex molecular architectures have led to more recent examples in the literature, ${ }^{10 e}$ however all examples to date have provided achiral products. We envisioned that the $N$-nosyl derivatives (1) of our newly-developed 5-allenyloxazolidinones could undergo decarboxylative cross-coupling under SuzukiMiyaura conditions to generate 2-substituted 1,3-dienes 2

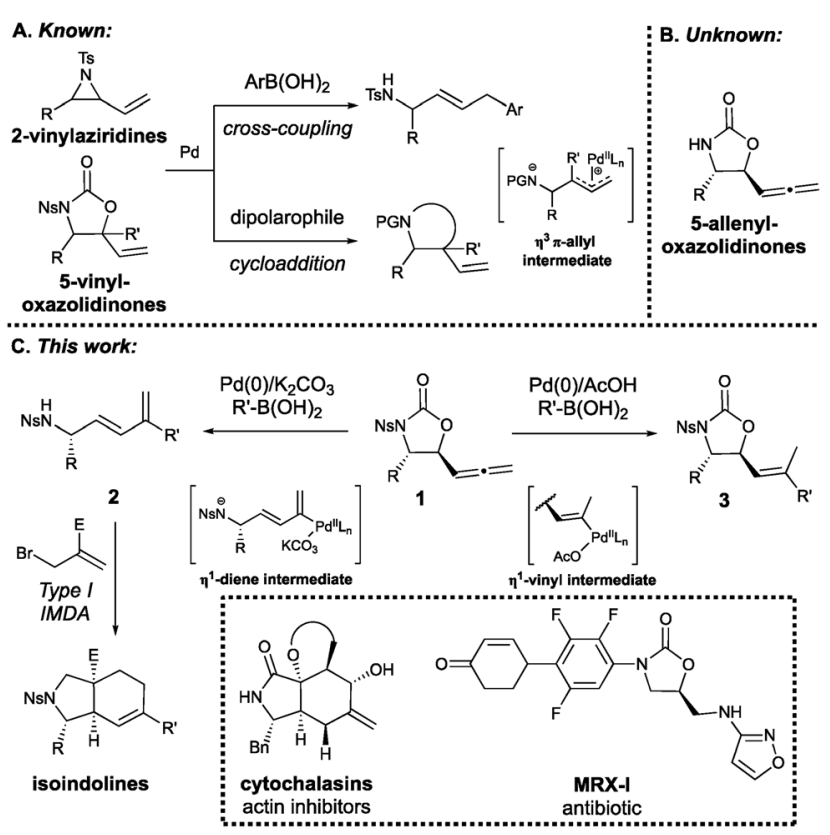

Scheme 1 (A) Known reactivity of 2-vinylaziridines and 5-vinyloxazolidinones. (B) Previously unknown 5-allenyloxazolidinones developed in the Hyland and Pyne groups. (C) Novel, divergent reactivity of 5-allenyloxazolidinones reported herein. 
bearing both a stereogenic centre and pendant a nitrogen atom: a system that is perfectly tailored for Type I intramolecular Diels-Alder (IMDA) reactions to give densely functionalized, stereodefined isoindoline scaffolds (Scheme 1C). A critical limitation of the powerful IMDA reaction ${ }^{\mathbf{1 1}}$ is the lack of synthetic routes to complex and stereodefined 1,3-diene substrates, ${ }^{12}$ highlighting the importance of the work reported herein. Interestingly, while optimizing the construction of these 1,3-dienes, exchanging the base for $\mathrm{AcOH}$ led to the exclusive formation of the substituted 5-vinyloxazolidinone scaffold 3 , bearing structural resemblance to oxazolidinone antibiotics such as linezolid, ranbezolid and the recently developed MRXI. ${ }^{13}$ It is now apparent that the novel class of enantioenriched allenyloxazolidinones developed in our group exhibits complementary reactivity to 2-vinylaziridines and 5-vinyloxazolidinones in the pursuit of stereodefined $\mathrm{N}$-heterocyclic scaffolds. Moreover, this system is capable of an elegant divergence in reactivity, exclusively giving rise to either $\mathrm{N}$-tethered, stereodefined 2-substituted 1,3-dienes or medicinally relevant substituted 5-vinyloxazolidinones by virtue of a single switch in additive, under mild conditions, in good to excellent yields and with high stereoselectivity and enantioretention.

The required 5-allenyloxazolidinone building blocks 1ad were prepared via our previously developed zinc-catalyzed allenylation of L- $\alpha$-amino aldehydes, ${ }^{7}$ then an $N$-nosyl group introduced to promote decarboxylative ring-opening. In order to develop and optimize the 1,3-diene synthesis, the valinederived allenyloxazolidinone 1a was subjected to SuzukiMiyaura conditions using $p$-methoxyphenylboronic acid as the cross-coupling partner and $\mathrm{Pd}_{2} \mathrm{dba}_{3} \cdot \mathrm{CHCl}_{3}$ as the $\mathrm{Pd}(0)$ source (Table 1). The desired 1,3-diene 2 a was obtained in good yield and stereoselectivity $(E: Z)$ in the absence of an additional ligand (Table 1, entry 1), however the introduction of a phosphine ligand significantly increased the stereoselectivity (entries 2-6). A bulky phosphine (entry 4) or phosphite (entry 6) ligand improved yield and stereoselectivity, prompting the use of the bulky phosphite ligand L (tris(2,4-di-tert-butylphenyl)phosphite). While the previous ligands left the product requiring multiple purifications, ligand $\mathrm{L}$ cleanly afforded the 1,3-diene after column chromatography while maintaining yield and stereoselectivity (entry 7). This, as well as being a relatively cheap, non-toxic and air-stable solid, left phosphite ligand $\mathrm{L}$ the optimal choice. While investigating the effect of other bases typically used in Suzuki-Miyaura type crosscouplings, it was found that KOAc promoted the formation of the directly cross-coupled 5-vinyloxazolidinone 3a (entry 8). Given the existing literature on $\mathrm{Pd}(0) / \mathrm{AcOH}$-catalyzed crosscoupling of boronic acids to allenes, ${ }^{14}$ it was suspected that this reaction was catalyzed by trace $\mathrm{AcOH}$. This was confirmed by the addition of 1.5 equivalents of $\mathrm{AcOH}$ (entry 9) and unlocked a divergent path to the 5-vinyloxazolidinone in excellent yield and stereoselectivity with low catalyst loading (entry 10), though the 1,3-diene required a slightly higher catalyst loading to maintain stereoselectivity and chemoselectivity (entries 11 and 12). The $E$ stereochemistry of the 1,3diene 2 a could be confirmed from its ${ }^{1} \mathrm{H}$ NMR spectrum, ${ }^{15}$ while X-ray crystallography provided unambiguous proof for the $E$ stereochemistry of the 5-vinyloxazolidinone 3a. It was confirmed via chiral HPLC that both reactions proceed with complete enantioretention ( $>99 \%$ ee).

Once the optimal conditions for the divergent synthesis of the 1,3-dienes or 5-vinyloxazolidinones had been established,

Table 1 Selected optimization of the divergent synthesis ${ }^{a}$

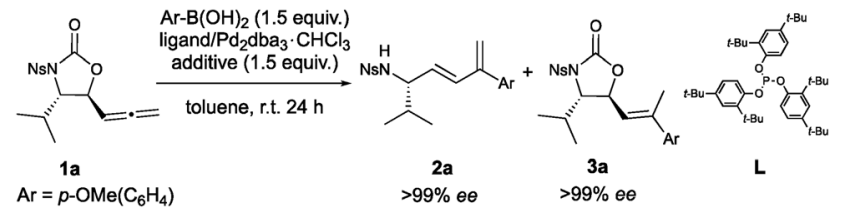

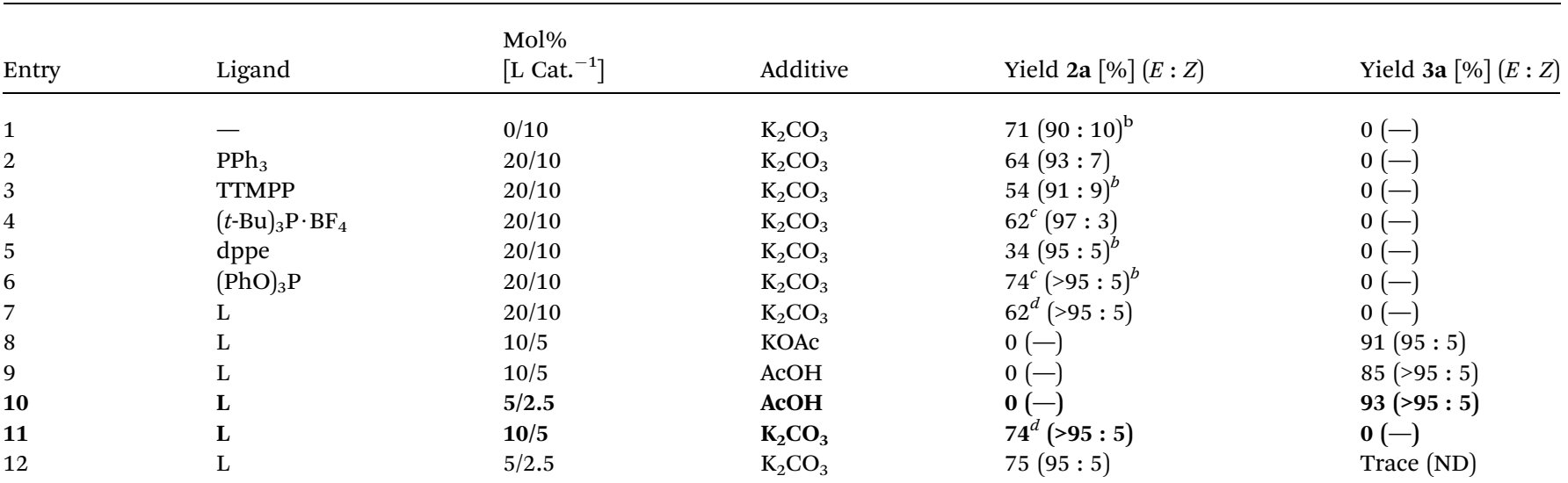

${ }^{a}$ A crystal structure was obtained for 1a (CCDC 1919153) and 3a (CCDC 1919154). ${ }^{b}$ Ratio $(E: Z)$ determined after purification. All other ratios determined from the ${ }^{1} \mathrm{H}$ NMR spectrum of the crude reaction mixture. ${ }^{c}$ Required further purification. Yield after recrystallization $=32 \%$ (entry 4), $20 \%$ (entry 6 ). ${ }^{d}$ Average yield. 
the substrate scope with respect to the boronic acid and the substituent at the stereogenic centre was investigated for both reactions. A range of arylboronic acids bearing electrondonating and withdrawing substituents were well-tolerated in the synthesis of the 1,3-dienes (Table 2). The sterically hindered nature of the ortho-substituted boronic acids likely impedes transmetallation ${ }^{16}$ (2c and $2 \mathrm{f}$ ) and is well known to drive protodeboronation, the resulting boric acid likely catalyzing the unexpected formation of the corresponding vinyloxazolidinone in the case of $2 \mathbf{c}$. In contrast, the highly electron-poor $m$ - and $p$ nitrophenylboronic acids gave the highest yields ( $2 \mathbf{d}$ and $2 \mathbf{e}$ ). An ester functionality, however, was not as well-tolerated (2i), though electron-poor boronic acids are known to undergo homocoupling ${ }^{17}$ and protodeboronation. ${ }^{18}$ Aryl substituents with halogen handles were able to be introduced $(2 \mathbf{g}$ and $2 \mathbf{h})$, though competitive oxidative addition to the $\mathrm{C}-\mathrm{Br}$ bond may explain the lower yield of desired product in the case of $\mathbf{2 g}$. Pleasingly, the scope was extended to heteroarylboronic acids (2k and 2l) and 1-phenylvinylboronic acid (2m), albeit in lower yield and stereoselectivity for the latter. Interestingly, $n$-butylboronic acid was successfully employed in the reaction (2n), which is significant considering the reduced reactivity of alkylboronic acids under Suzuki-Miyaura conditions (though protocols have been developed to accommodate these). ${ }^{19}$ With respect to the substituent at the stereogenic centre, the corresponding alanine, leucine and phenylalanine-derived 1,3dienes were synthesized in moderate yield and excellent stereoselectivity, using $m$-nitrophenylboronic acid as the coupling partner $(\mathbf{2 0 -}-\mathbf{q}){ }^{20}$

Table 2 Substrate scope for the 1,3-diene synthesis ${ }^{a}$

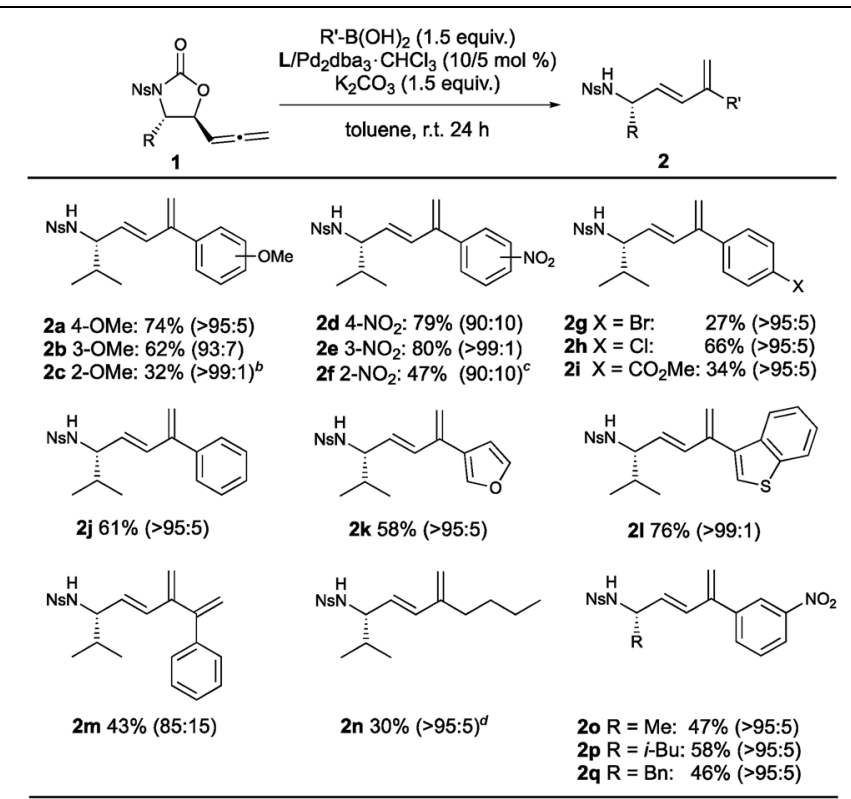

${ }^{a} E: Z$ ratio shown in parentheses. ${ }^{b}$ Corresponding 5vinyloxazolidinone $3 \mathbf{c}$ obtained as major product $(83 \%,>95: 5, E: Z)$. ${ }^{c}$ Inseparable mixture $(86: 14)$ of product and dimerized starting material 4 (Scheme 2B), respectively. Yield of $2 \mathrm{f}$ calculated via ${ }^{1} \mathrm{H}$ NMR spectrum of the mixture. ${ }^{d}$ Required resubjection to the reaction conditions to consume starting material and enable purification.
A range of arylboronic acids were also well-tolerated in the synthesis of the 5-vinyloxazolidinones (Table 3), with some notable differences in reactivity in comparison to the 1,3-diene synthesis. For example, while the electron-rich boronic acids (3a-c, including the sterically hindered ortho-substituted example 3c) furnished the corresponding products in good to excellent yields, the electron-poor examples were mostly unreactive (3d-f) apart from $m$-nitrophenylboronic acid (3e, where the resonance effect of the nitro group was less effective at the boron-substituted carbon), though a higher catalyst loading and resubjection to the reaction conditions was required for this reaction to proceed to completion. ${ }^{21}$ Aryl substituents with functionalizable handles such as halogens ( $3 \mathrm{~g}$ and $\mathbf{3 h}$ ) and an ester (3i) were introduced in high yields, as were heteroaryl groups (3k and $\mathbf{3 1}$ ), with the benzo[b]thiophene analogue $\mathbf{3 l}$ furnished in almost quantitative yield. It was found that 1-phenylvinylboronic acid did not cleanly afford the corresponding product as in the 1,3-diene synthesis, however $(E)$ styrylboronic acid was well tolerated with excellent stereoselectivity (3m). In contrast to the 1,3-diene synthesis, $n$-butylboronic acid was unreactive (3n). With respect to the substituent at the stereogenic centre, the alanine, leucine and

Table 3 Substrate scope for the 5-vinyloxazolidinone synthesis ${ }^{a}$

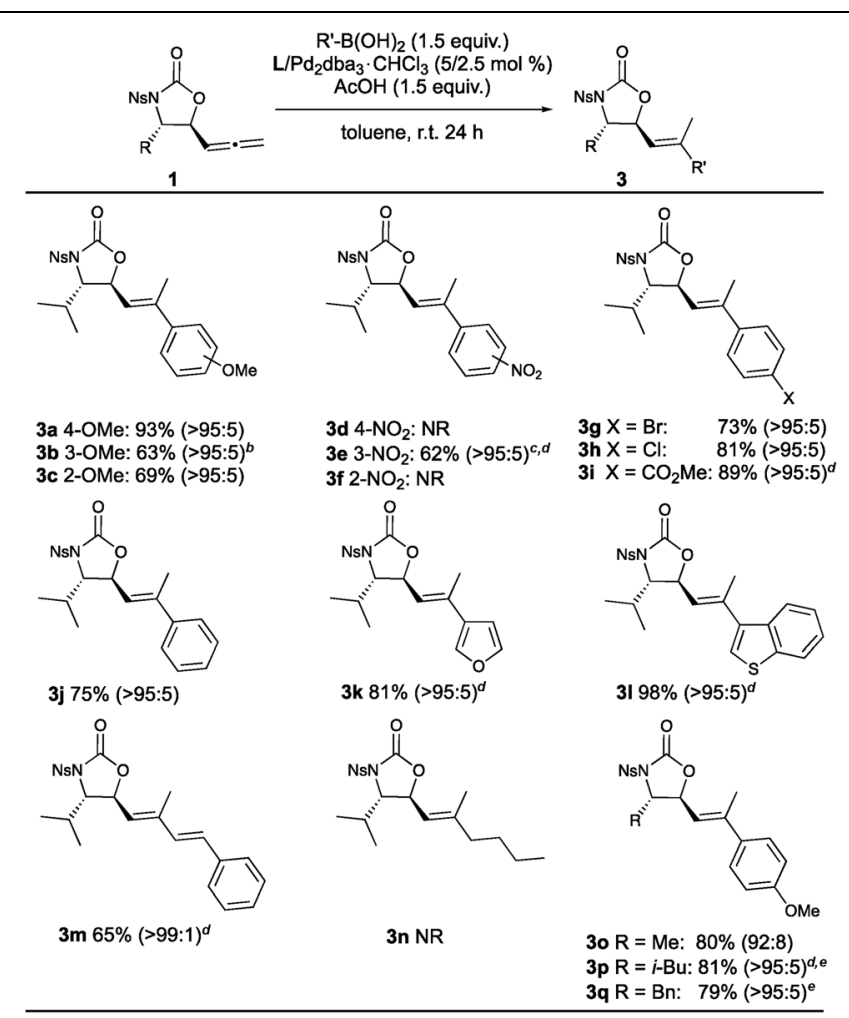

${ }^{a} E: Z$ ratio shown in parentheses. ${ }^{b} 93 \%$ conversion. Starting material removed via recrystallization in chloroform/hexane following column chromatography. ${ }^{c}$ Ligand/catalyst loading increased to $10 / 5 \mathrm{~mol} \%$, respectively. ${ }^{d}$ Required resubjection to the reaction conditions to consume starting material and enable purification. ${ }^{e}$ Obtained as a mixture of diastereoisomers due to $\mathbf{1 c}$ and $\mathbf{1 d}$ containing a minor diastereoisomer, however $\mathrm{dr}$ could be increased to 15.3:1 (from $8.0: 1 \mathrm{dr}, 3 \mathbf{p}$ ) and $9.7: 1$ (from $3.2: 1 \mathrm{dr}, 3 \mathbf{q}$ ) upon purification. 
phenylalanine-derived products were able to be synthesized in high yield and stereoselectivity (3o-q).

The proposed reaction mechanisms for both syntheses are shown in Scheme 2A. The origin of divergence in the reactivity of the 5-allenyloxazolidinone arises from the formation of either intermediate I or V. During 1,3-diene formation, $\operatorname{Pd}(0)$ likely undergoes decarboxylative oxidative addition to the internal allene carbon, furnishing the $\mathrm{Pd}$ (II) intermediate I as the $E$ stereoisomer, stabilized by a carbonate anion. This intermediate is thought to bind $\eta^{1}$ rather than $\eta^{3}$, which is supported both in the literature $\mathbf{1 0 a}^{\mathbf{1 0} \boldsymbol{b}}$ and by the appearance of dimerized starting material 4 (Scheme 2B) during the synthesis of $\mathbf{2 f}$, the dendraline core of $\mathbf{4}$ likely forming via the same $\eta^{1}$ coordination mode. In contrast, the mechanism for the formation of the 5-vinyloxazolidinone begins with oxidative addition of $\mathrm{Pd}(0)$ to $\mathrm{AcOH}$ to form complex IV, which undergoes a concerted hydropalladation to form the $\operatorname{Pd}(\mathrm{II})$ intermediate V. This mechanism is supported by mass spectrometry studies conducted by Guo and $\mathrm{Ma},{ }^{22}$ and previous work by $\mathrm{Ma}^{\mathbf{1 4 b}}$ supports that the $E$ stereochemistry arises from facially-selective coordination of $\operatorname{Pd}(\mathrm{II})$ opposite to the substituent at the stereogenic centre, and that the regioselectivity is controlled by delivery of the hydride to the relatively less sterically hindered terminal allene carbon (Scheme 2C). The mechanism of transmetalation differs between the two syntheses and this may explain the differing relative reactivity of the electron-poor arylboronic acids. Under basic conditions, the formation of the activated boronate II likely precedes transmetalation. ${ }^{23}$ It is well known that electron-poor arylboronic acids facilitate this pathway due to their increased Lewis acidity, and this is reflected in the high yields of the $\mathrm{m}$ and $p$-nitrophenyl 1,3-dienes. The 5-vinyloxazolidinone synthesis, however, occurs in the absence of an added base and therefore a direct transmetalation likely occurs instead, in which the electron-poor nature of the nitrophenylboronic acids renders them unreactive. Both syntheses conclude with a reductive elimination, delivering the organic moiety to the 1,3-diene III or 5-vinyloxazolidinone VI and regenerating the $\operatorname{Pd}(0)$ catalyst. Critically, a control experiment showed that treatment of the 5-vinyloxazolidinone with the $\operatorname{Pd}(0)$-catalyst system and $\mathrm{K}_{2} \mathrm{CO}_{3}$ did not result in formation of the 1,3diene via elimination, indicating the 5 -vinyloxazolidinone is not a precursor to the 1,3-diene.

As previously mentioned, the 5-vinyloxazolidinones may serve as structural analogues to existing oxazolidinone antibiotics, bearing the correct stereochemical scaffold and an unsaturated alkene moiety suitable for further functionalization. The 1,3-dienes, however, can act as powerful substrates in the Type I IMDA reaction to give more complex molecular scaffolds. In order to demonstrate this, a dienophile was tethered to the $p$-methoxyphenyl system 2 a via $N$-alkylation with ethyl 2-(bromomethyl)acrylate (Scheme 3 ). It was found that the alkylation and subsequent IMDA reaction occurred in a one-pot

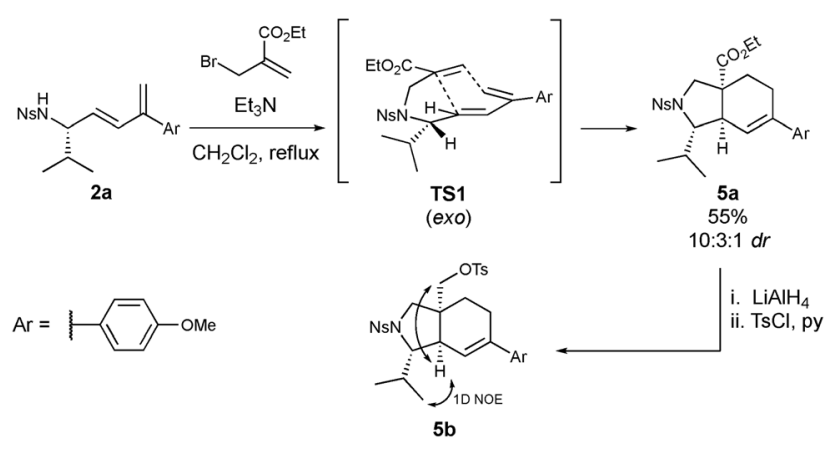

Scheme 3 Applications of the chiral 1,3-dienes in the IMDA reaction and elucidation of stereochemistry.
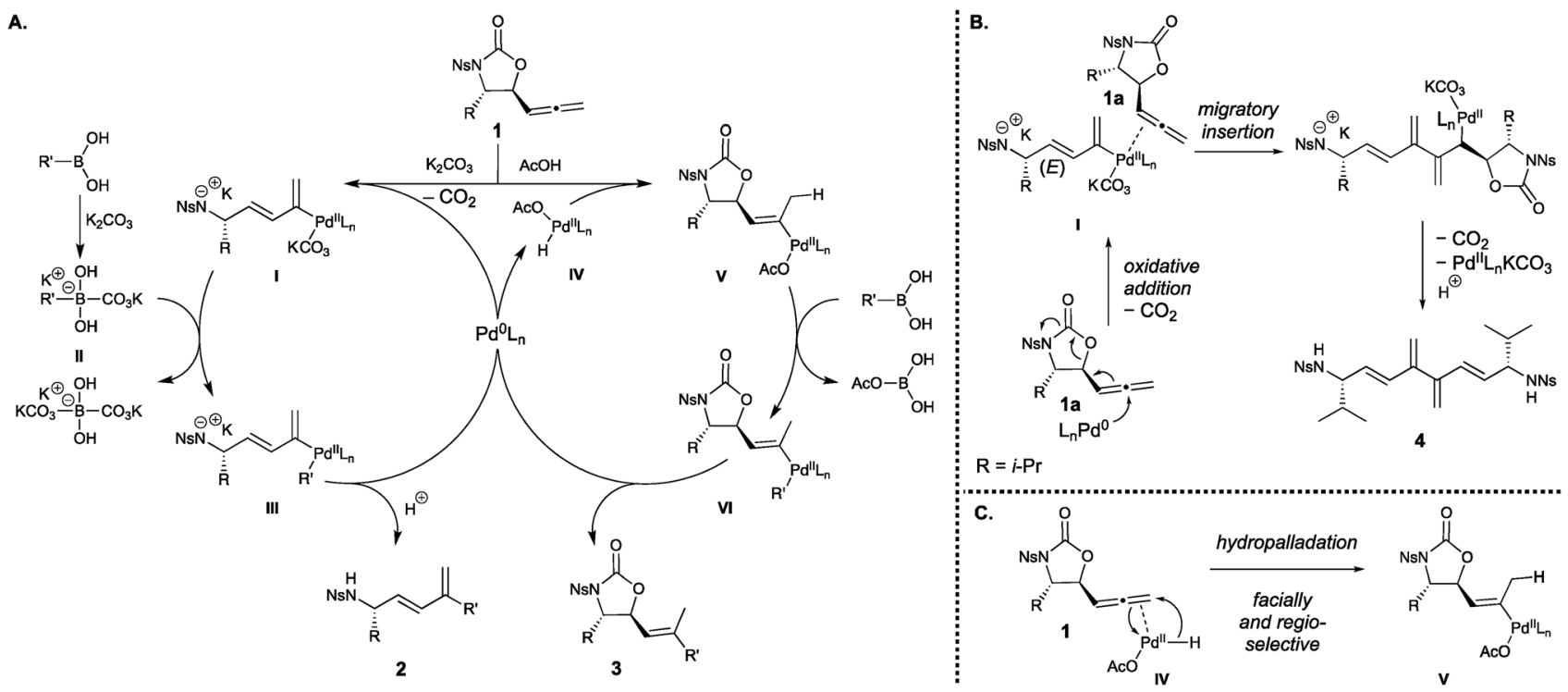

Scheme 2 (A) Proposed reaction mechanism for the divergent syntheses. (B) Proposed reaction mechanism for the formation of dimer 4. (C) Origin of $E: Z$ stereoselectivity during hydropalladation. 
fashion to furnish the isoindoline derivative 5a. The stereochemistry of the major diastereoisomer of this isoindoline system was determined via 1D NOE experiments and supported by computational data. The major diastereoisomer was able to be isolated via column chromatography after reducing the ethyl ester and introducing an $O$-tosyl group to the resulting alcohol to give derivative $\mathbf{5 b}$. The $1 \mathrm{D}$ NOE experiments conducted on $\mathbf{5 b}$ revealed strong correlations between the bridgehead proton and the $\mathrm{CH}_{2}$-OTs protons, indicating the formation of a cisfused system. The strong correlation between the bridgehead proton and the isopropyl methyl protons indicated that both substituents were positioned on the same face, as did the lack of correlation between the existing stereogenic proton and the $\mathrm{CH}_{2}$-OTs protons. The interpretation of the 1D NOE data was further supported by the interproton distances estimated by density functional theory calculations (see ESI $\dagger$ ). The stereochemical outcome can be rationalized in terms of the proposed transition state TS1, the exo configuration of which is not uncommon in IMDA processes. ${ }^{24}$ This isoindoline core, including the stereochemical outcome, is structurally similar to that of the cytochalasin natural products (Scheme 1C), which are known to exhibit activity in actin polymerization and other cellular processes, ${ }^{25}$ giving heavy precedent to the medicinal relevance of these systems.

\section{Conclusions}

In summary, the $\mathrm{Pd}(0)$-catalyzed cross-coupling of boronic acids to enantioenriched allenyloxazolidinones has been explored, giving rise to chiral 1,3-dienes and vinyloxazolidinones. Not only is this a divergent process that can be tightly controlled by a single switch in additive, but the allenyloxazolidinone itself is an entirely new building block that can now complement known related systems such as vinylaziridines and vinyloxazolidinones. A synthetic route to highly complex and stereodefined vinyloxazolidinones has been established, which can now serve as potential analogues to existing oxazolidinone antibiotics. Furthermore, we have developed a route to stereodefined, N-tethered 1,3-dienes under mild conditions, the complex nature of which has left such systems underexplored in the literature, as they are inherently difficult to synthesize. We have demonstrated that these substrates can now be employed in the powerful intramolecular Diels-Alder reaction to form highly complex and medicinally relevant isoindoline scaffolds.

\section{Conflicts of interest}

There are no conflicts to declare.

\section{Acknowledgements}

This research was supported in part by the Australian Government through the Australian Research Council's Discovery Projects funding scheme (project DP180101332). The University of Wollongong is also acknowledged for generous partial funding of this research. The NCI National Facility is acknowledged for providing the computing time.

\section{Notes and references}

1 For a review on the general reactivity of vinylaziridines, see: H. Ohno, Chem. Rev., 2014, 114, 3703.

2 For examples of Pd-catalyzed cross-coupling reactions of vinylaziridines, see: (a) J. Kjellgren, J. Aydin, O. A. Wallner, I. V. Saltanova and K. J. Szabó, Chem.-Eur. J., 2005, 11, 5260; (b) J. Yin, T. Mekelburg and C. J. T. Hyland, Org. Biomol. Chem., 2014, 12, 9113.

3 For reviews on cycloaddition reactions of vinylaziridines, see: (a) A. L. Cardoso and T. M. V. D. Pinho e Melo, Eur. J. Org. Chem., 2012, 6479; (b) E. A. Ilardi and J. T. Njardarson, J. Org. Chem., 2013, 78, 9533; (c) J.-J. Feng and J. Zhang, ACS Catal., 2016, 6, 6651; (d) B. D. W. Allen, C. P. Lakeland and J. P. A. Harrity, Chem.-Eur. J., 2017, 23, 13830.

4 For a recent example from our group of a Pd-catalyzed [3+2] cycloaddition of $\mathrm{N}$-tosyl-2-vinylaziridine to 3-nitroindoles to give a medicinally relevant pyrroloindoline scaffold, see: D. J. Rivinoja, Y. S. Gee, M. G. Gardiner, J. H. Ryan and C. J. T. H. Hyland, ACS Catal., 2017, 7, 1053.

5 For examples of Pd-catalyzed cycloaddition reactions of 5vinyloxazolidinones, see: (a) J. G. Knight, P. A. Stoker, K. Tchabanenko, S. J. Harwood and K. W. M. Lawrie, Tetrahedron, 2008, 64, 3744; (b) K. Ohmatsu, N. Imagawa and T. Ooi, Nat. Chem., 2014, 6, 47; (c) K. Ohmatsu, S. Kawai, N. Imagawa and T. Ooi, ACS Catal., 2014, 4, 4304. 6 For reviews on allene reactivity, see: (a) S. Ma, Chem. Rev., 2005, 105, 2829; (b) S. Yu and S. Ma, Angew. Chem., Int. Ed., 2012, 51, 3074. For a recent example of a palladiumcatalyzed reaction of allenes leading to a wide range of synthetic applications, see: ; (c) B. M. Trost, D. Zell, C. Hohn, G. Mata and A. Maruniak, Angew. Chem., Int. Ed., 2018, 57, 12916; Angew. Chem., 2018, 130, 13098.

7 F. Zamani, S. G. Pyne and C. J. T. Hyland, J. Org. Chem., 2017, 82, 6819.

8 F. Zamani, R. Babaahmadi, B. F. Yates, M. G. Gardiner, A. Ariafard, S. G. Pyne and C. J. T. Hyland, Angew. Chem., Int. Ed., 2019, 58, 2114; Angew. Chem., 2019, 131, 2136.

9 For reviews on Pd-catalyzed reactions of allenes, see: $(a)$ R. Zimmer, C. U. Dinesh, E. Nandanan and F. A. Khan, Chem. Rev., 2000, 100, 3067; (b) T. Lechel, F. Pfrengle, H.-U. Reissig and R. Zimmer, ChemCatChem, 2013, 5, 2100.

10 For selected examples of $\operatorname{Pd}(0)$-catalyzed reactions of allenylcarbinol derivatives with boronic acids to form 1,3dienes, see: (a) T. Moriya, T. Furuuchi, N. Miyaura and A. Suzuki, Tetrahedron, 1994, 50, 7961; (b) M. Yoshida, T. Gotou and M. Ihara, Chem. Commun., 2004, 1124; (c) T. Liu, J. Dong, S.-J. Cao, L.-C. Guo and L. Wu, RSC Adv., 2014, 4, 61722; (d) Y.-Z. Chen, L. Zhang, A.-M. Lu, F. Yang and L. Wu, J. Org. Chem., 2015, 80, 673; (e) D. J. Lippincott, R. T. H. Linstadt, M. R. Maser, F. Gallou and B. H. Lipshutz, Org. Lett., 2018, 20, 4719.

11 For reviews on the intramolecular Diels-Alder reaction, see: (a) G. Brieger and J. N. Bennett, Chem. Rev., 1980, 80, 63; (b) 
A. G. Fallis, Can. J. Chem., 1984, 62, 183; (c) D. Craig, Chem. Soc. Rev., 1987, 16, 187; (d) K.-I. Takao, R. Munakata and K.-I. Tadano, Chem. Rev., 2005, 105, 4779; (e) M. Juhl and D. Tanner, Chem. Soc. Rev., 2009, 38, 2983; (f) P. T. Parvatkar, H. K. Kadam and S. G. Tilve, Tetrahedron, 2014, 70, 2857.

12 A number of other synthetic routes to complex, chiral 1,3dienes have previously been reported. For selected examples using rhodium catalysis, see: (a) P.-S. Wang, P. Liu, Y.-J. Zhai, H.-C. Lin, Z.-Y. Han and L.-Z. Gong, J. Am. Chem. Soc., 2015, 137, 12732; (b) S. E. Korkis, D. J. Burns and H. W. Lam, J. Am. Chem. Soc., 2016, 138, 12252; (c) J. D. Dooley and H. W. Lam, Chem.-Eur. J., 2018, 24, 4050; (d) D. Bai, J. Xia, F. Song, X. Li, B. Liu, L. Liu, G. Zheng, X. Yang, J. Sun and X. Li, Chem. Sci., 2019, 10, 3987. For an example using palladium catalysis, see: ; $(e)$ G. T. Crisp and M. G. Gebauer, J. Org. Chem., 1996, 61, 8425. For an additional example, see ref. $6 c$. For an example using a chiral vinylstannane, see: ; $(f)$ A. D. Brosius, L. E. Overman and L. Schwink, J. Am. Chem. Soc., 1999, 121, 700. For an example using a $\mathrm{TiCl}_{4}-$ promoted electrophilic substitution of axially chiral allenes, see: ; $(g)$ M. Ogasawara, K. Ueyama, T. Nagano, Y. Mizuhata and T. Hayashi, Org. Lett., 2003, 5, 217. For an example using ring-closing metathesis of enantioenriched enynes, see: ; $(h)$ M. J. Garcia-Muñoz, A. Sirvent, F. Foubelo and M. Yus, An. Acad. Bras. Cienc., 2018, 90, 1059. For selected transition metal-free examples, see: ; $i$ ) M. J. Lilly and M. S. Sherburn, Chem. Commun., 1997, 967; (j) R. Fernández de la Pradilla, I. Colomer and A. Viso, Org. Lett., 2012, 14, 3068 (Overman rearrangement).

13 C.-R. Li, Q.-Q. Zhai, X.-K. Wang, X.-X. Hu, G.-Q. Li, W.-X. Zhang, J. Pang, X. Lu, H. Yuan, M. F. Gordeev, L.-T. Chen, X.-Y. Yang and X.-F. You, Antimicrob. Agents Chemother., 2014, 58, 2418.

14 For selected examples of $\mathrm{Pd} / \mathrm{AcOH}$-catalyzed addition of boronic acids to allenes, see: $(a)$ C. Ho Oh, T. W. Ahn and R. Reddy, Chem. Commun., 2003, 2622; (b) S. Ma, N. Jiao and L. Ye, Chem.-Eur. J., 2003, 9, 6049; (c) S. Ma, H. Guo and F. Yu, J. Org. Chem., 2006, 71, 6634; (d) H. Guo and S. Ma, Synthesis, 2007, 17, 2731; (e) M. Yoshida, K. Matsuda, Y. Shoji, T. Gotou, M. Ihara and K. Shishido, Org. Lett., 2008, 10, 5183. For applications of this reactivity in the synthesis of natural products, see: ; $(f)$ M. Yoshida, Y. Shoji and K. Shishido, Org. Lett., 2009, 6, 1441; $(g)$ M. Yoshida, Y. Shoji and K. Shishido, Tetrahedron, 2010, 66, 5053; (h) M. Yoshida, T. Kasai, T. Mizuguchi and K. Namba, Synlett, 2014, 25, 1160.

15 The internal alkene proton adjacent to the aryl group exhibited a coupling constant of $15.6 \mathrm{~Hz}$ for the $E$ isomer and $11.8 \mathrm{~Hz}$ for the $Z$ isomer.

16 T. E. Barder, S. D. Walker, J. R. Martinelli and S. L. Buchwald, J. Am. Chem. Soc., 2005, 127, 4685.

17 M. S. Wong and X. L. Zhang, Tetrahedron Lett., 2001, 42, 4087.

18 H. G. Kuivila, J. F. Reuwer Jr and J. A. Mangravite, J. Am. Chem. Soc., 1964, 86, 2666.

19 For selected examples of Suzuki-Miyaura cross-coupling procedures accommodating alkylboronic acids and their derivatives, see: (a) J. H. Kirchhoff, M. R. Netherton, I. D. Hills and G. C. Fu, J. Am. Chem. Soc., 2002, 124, 13662; (b) I. Kondolff, H. Doucet and M. Santelli, Tetrahedron, 2004, 60, 3813; (c) L. Li, S. Zhao, A. JoshiPangu, M. Diane and M. R. Biscoe, J. Am. Chem. Soc., 2014, 136, 14027. For a nickel-catalysed example, see: ; $(d) \mathrm{Z}$. Lu, A. Wilsily and G. C. Fu, J. Am. Chem. Soc., 2011, 133, 8154.

20 It is suspected that these products were more prone to polymerization than the corresponding valine derivatives, as reflected in the isolated yields, despite the use of $\mathrm{pH}^{-}$ neutral conditions during purification.

21 It should be noted that other examples required resubjection to the reaction conditions despite high conversion, as even traces of starting material were unable to be separated from the products via column chromatography. See ESI $\dagger$ for details.

22 R. Qian, H. Guo, Y. Liao, Y. Guo and S. Ma, Angew. Chem., Int. Ed., 2005, 44, 4771; Angew. Chem., 117, 2005, 4849.

23 For a review covering mechanisms and factors affecting transmetalation, see: A. J. J. Lennox and G. C. Lloyd-Jones, Angew. Chem., Int. Ed., 2013, 52, 7362.

24 For an example of an intramolecular Diels-Alder reaction proceeding through an exo transition state, see: C. I. Turner, R. M. Williamson, M. N. Paddon-Row and M. S. Sherburn, J. Org. Chem., 2001, 66, 3963.

25 K. Scherlach, D. Boettger, N. Remme and C. Hertweck, Nat. Prod. Rep., 2010, 27, 869. 